\title{
Urinary balantidiasis in a patient with systemic lupus erythematosus and lupus nephritis: a case report
}

Pongsakorn Martviset ${ }^{1 *} \mathbb{D}$, Kridsada Sirisabhabhorn², Supaporn Pumpa ${ }^{2}$, Pochong Rhongbutsri ${ }^{1}$, Aree Taylor $^{1}$ and Walter R. J. Taylor ${ }^{3,4}$

\begin{abstract}
Background: Balantidium coli, a parasitic unicellular ciliate, often causes asymptomatic balantidiasis of the colon, but extraintestinal disease may occur rarely in immunosuppressed individuals. Renal balantidiasis associated with systemic lupus erythematosus has not been reported before.
\end{abstract}

Case presentation: We present a case of a 48-year-old Thai woman who presented with nephrotic syndrome due to systemic lupus erythematosus-related nephritis. Initially, few B. coli cysts were found in urine sediment, but these increased substantially following treatment with prednisolone. She made an uneventful recovery with 10 days of oral tetracycline therapy. No B. coli cysts were found in her stool.

Conclusion: The route of infection in our patient was unclear but is likely to have been orofecal. Neither her infection nor its treatment caused a deterioration in her renal function.

Keywords: Urinary balantidiasis, Systemic lupus erythematosus, Prednisolone

\section{Background}

Balantidium coli (Neobalantidium coli) is a large, unicellular, ciliated parasite that infects mainly the gastrointestinal tract of humans and several mammals, such as wild pigs, cattle, sheep, and goats [1]. B. coli has two stages: the trophozoite and cyst. Trophozoites are irregularly shaped and are the living stage of the parasite, whereas the cyst is the infective stage and has a thick wall for protection from the environment [2-4].

Humans can be infected by ingesting mature cysts that infect water and food. Once ingested, the cyst releases trophozoites in the duodenum, which then mature and migrate to the colon, where they replicate by transverse binary fission and, less frequently, by conjugation. Some

\footnotetext{
* Correspondence: pong_m@tu.ac.th

'Division of Parasitology, Department of Preclinical Sciences, Faculty of Medicine, Thammasat University, Pathumthani 12120, Thailand

Full list of author information is available at the end of the article
}

trophozoites may invade the colonic wall and multiply to cause colonic ulcers and a dysenteric syndrome similar to that of Entamoeba histolytica. Trophozoites generally encyst in the colon and are passed into the environment with the feces $[2,4]$.

The estimated global prevalence rates in humans vary between $0.02 \%$ and $1 \%$, with higher rates reported in animals, such as pigs, in which is as high as 93\% [2, 4]. Regions and countries with the highest human prevalence rates are Latin America, the Philippines, Papua New Guinea, and the Middle East, where rates of up to $29 \%$ have been reported in pig farmers [2, 5-7]. The majority of infections are asymptomatic and are probably due to avirulent or low-virulence strains. Dysentery is uncommon and is thought to be related to the immune status of the individual [8-10]. Extraintestinal balantidiasis is rare but has been reported in several organs, such as the liver, lungs, and genitourinary tract, in immunodeficient and 
otherwise healthy patients $[8,11,12]$. There are few case reports of urinary balantidiasis occurring in patients with steroid-treatedchronic obstructive pulmonary disease, patients with chronic renal failure, and in two cases without underlying diseases [13]. There is no previous report of urinary balantidiasis in patients with systemic lupus erythematosus (SLE). We report a case of a patient with SLE who was found to have incidental urinary balantidiasis on the basis of routine urine testing.

\section{Case presentation}

A 48-year-old Thai woman with congenital mutism presented with a 3-month history of intermittent swelling of both lower limbs. She was otherwise well and did not report joint pain, headache, photophobia, rash, dyspnea, orthopnea, palpitations, hair loss, or bowel symptoms. Her appetite was normal. She had no history of clinically significant underlying diseases; she was not receiving any drug treatments; and she did not drink alcohol or smoke. Her physical examination revealed that she was well; her weight was $41 \mathrm{~kg}$, and her body temperature was $37.2^{\circ} \mathrm{C}$, pulse rate was 103 beats/minute, blood pressure was $116 / 70 \mathrm{mmHg}$, and respiratory rate was 20 breaths/minute. She had no abnormal findings of her head, ears, eyes, nose, throat, heart, lungs, and abdomen. The only abnormal sign was bilateral pitting edema $3+$ below the knee without erythema and increased warmth.

Routine laboratory tests (Table 1) showed that she had a mild microcytic anemia (hemoglobin $9.4 \mathrm{mg} / \mathrm{dl}$, mean corpuscular volume $73 \mathrm{fl}$ ). Her serum total protein and albumin concentrations were low, but she had hyperglobulinemia and raised liver enzymes (aspartate aminotransferase, alanine aminotransferase, and alkaline phosphatase). Her serum creatinine was $0.82 \mathrm{mg} / \mathrm{dl}$, for an estimated glomerular filtration rate (eGFR) of $85.49 \mathrm{ml} / \mathrm{min} / 1.73 \mathrm{~m}^{2}$, blood urea nitrogen (BUN) $21.20 \mathrm{mg} / \mathrm{dl}$, sodium $137 \mathrm{mEq} / \mathrm{L}$, potassium $4.0 \mathrm{mEq} / \mathrm{L}$, and chloride $103 \mathrm{mEq} / \mathrm{L}$. Her hepatitis (anti-hepatitis $\mathrm{C}$ virus antibodies, hepatitis B surface antigen) and human immunodeficiency virus serology results were negative.

Her urine was yellow and turbid, and dipstick urinalysis (Roche Diagnostics, Mannheim, Germany) demonstrated a specific gravity of 1.021, $\mathrm{pH} 6.0$, protein $3+$, blood 3+, red blood cells 20-30 cells/high-power field (HPF), white blood cells 5-10 cells/HPF. Urine microcopy of the urine sediment showed few fine granular casts $0-1$ /low-power field (LPF) and coarse granular casts 5-10/LPF. By spot urine, her total protein and creatinine were $1.339 .4 \mathrm{mg} / \mathrm{dl}$ and $143.79 \mathrm{mg} / \mathrm{dl}$, respectively.

Suspecting chronic kidney disease secondary to an autoimmune disease, we performed additional investigations, which revealed a positive antinuclear antibody. For the titer of 1280, it revealed the homogeneous and fine speckled patterns meanwhile the nucleolar, peripheral, and cytoplasm patterns were observed in the titer of less than 80. The patient's C3 complement concentration was 50.0 $\mathrm{mg} / \mathrm{dl}$ (normal $81-157 \mathrm{mg} / \mathrm{dl}$ ), and her $\mathrm{C} 4$ complement concentration was $<8.0 \mathrm{mg} / \mathrm{dl}$ (normal $13-39 \mathrm{mg} / \mathrm{dl}$ ). Her urinary protein excretion over 24 hours was $9.3 \mathrm{~g}$, meeting the case definition of nephrotic proteinuria. The result of a second urine analysis was similar to that of the first analysis (Table 1). The patient was diagnosed with clinically suspected SLE with lupus nephritis. A referral for a renal biopsy was made, and she was prescribed prednisolone 1 $\mathrm{mg} / \mathrm{kg}$. Two days later, a third urinalysis was performed (Table 1). In addition to similar results as before, several rapidly moving, large, ovoid-shaped ciliated parasites were seen by video clip/light microscopy; these findings were confirmed by two additional microscopic analyses of her urine sediment. No antiparasitic treatment was given, and she was asked to come for follow-up 2 weeks later.

At follow-up, a fourth urine analysis was done (Table $1)$, and a spot urine protein $(1679.0 \mathrm{mg} / \mathrm{dl})$ and creatinine $(100.34 \mathrm{mg} / \mathrm{dl})$ were measured. Serum BUN and creatinine were 37.5 and $1.48 \mathrm{mg} / \mathrm{dl}$, respectively. Numerous motile, ciliated trophozoites were seen in three consecutive urine samples by wet preparation and Wright-Giemsa staining that were identified as B. coli (Fig. 1). Three daily stool examinations by formalin-ethyl acetate concentration were negative for ova, cysts, and parasites. She was prescribed tetracycline $500 \mathrm{mg}$ four times daily for 10 days, after which the result of a posttreatment urine examination was negative for B. coli.

\section{Discussion}

Balantidiasis is usually an asymptomatic infestation of the colon, but symptoms may manifest in patients who are immunosuppressed, and such patients may also experience systemic involvement [2, 4]. We hypothesize that our patient with SLE with renal B. coli was an asymptomatic carrier, that invasion of the urinary tract probably took place because of her SLE, and that this invasion increased after prednisolone was prescribed, as evidenced by a greater number of $B$. coli trophozoites in her urine analysis. She made an uneventful recovery with 10 days of tetracycline.

Urinary balantidiasis is rare. The first reported case in 2007 was in a 60-year-old Indian man who complained of fever, lower abdominal pain, dysuria, and urinary frequency [14]. He had no underlying disease and no history of contact with pigs [15]. In other case reports, all patients had an underlying immunocompromising disease such as diabetes mellitus, steroid-treated chronic obstructive pulmonary disease, and chronic kidney disease [14-18], where the urinary balantidiasis was accidentally found during the urinalysis.

Our patient lived in urban Bangkok and had no contact with pigs. Thus, the most likely route of infection was 
Table 1 Selected routine laboratory findings

\begin{tabular}{|c|c|c|c|c|c|c|}
\hline Parameters & Visit 1 & Visit 2 & Visit 3 & Visit 4 & Post-treatment & Reference values \\
\hline \multicolumn{7}{|l|}{ Hematology } \\
\hline $\mathrm{Hb}(\mathrm{g} / \mathrm{dl})$ & 9.4 & 9.2 & 8.7 & - & - & $12-15$ \\
\hline Hct (\%) & 29.7 & 28.4 & 26.3 & - & - & $36-45$ \\
\hline MCV (fl) & 73 & 68 & 65 & - & - & $80-96$ \\
\hline WBC count $\left(\times 10^{9}\right.$ cells/L) & 6.8 & 6.4 & 5.3 & - & - & $4-10$ \\
\hline \multicolumn{7}{|l|}{ Biochemistry } \\
\hline Total protein (mg/dl) & 6.2 & - & - & - & - & $6.4-8.3$ \\
\hline Albumin (mg/dl) & 1 & - & - & - & - & $3.5-5$ \\
\hline Globulin (mg/dl) & 5.2 & - & - & - & - & $2.3-2.8$ \\
\hline AST (IU/L) & 159 & - & - & - & - & $<42$ \\
\hline $\mathrm{ALT}(\mathrm{IU} / \mathrm{L})$ & 72 & - & - & - & - & $<40$ \\
\hline ALP (IU/L) & 258 & - & - & - & - & $32-92$ \\
\hline Creatinine (mg/dl) & - & 0.82 & 0.84 & 1.48 & 0.88 & $0.6-1.3$ \\
\hline $\mathrm{eGFR}\left(\mathrm{ml} / \mathrm{min} / 1.73 \mathrm{~m}^{2}\right)$ & - & 85.49 & 83.03 & 41 & 84.55 & $>125$ \\
\hline Blood urea nitrogen (mg/dl) & - & 21.2 & 23.27 & 37.5 & - & $10-20$ \\
\hline \multicolumn{7}{|l|}{ Urinalysis } \\
\hline Color & Yellow & Yellow & Yellow & Yellow & Yellow & Colorless to amber \\
\hline Appearance & Turbid 2+ & Turbid 2+ & Turbid + & Turbid + & Clear & Clear \\
\hline Specific gravity & 1.021 & 1.04 & 1.022 & 1.017 & 1.01 & $1.003-1.030$ \\
\hline $\mathrm{pH}$ & 6 & 6 & 6 & 7.5 & 6 & $5.5-6.5$ \\
\hline Protein & $3+$ & $4+$ & $4+$ & $4+$ & $3+$ & Negative \\
\hline Blood & $3+$ & $3+$ & $2+$ & $2+$ & $1+$ & Negative \\
\hline Leukocyte esterase & $1+$ & $2+$ & $2+$ & $2+$ & Negative & Negative \\
\hline RBC (cells/HPF) & $20-30$ & $20-30$ & $5-10$ & $30-50$ & $5-10$ & $0-1$ \\
\hline WBC (cells/HPF) & $5-10$ & $>100$ & $>100$ & $>100$ & $5-10$ & $0-5$ \\
\hline Fine granular cast (/LPF) & $0-1$ & - & - & - & - & Negative \\
\hline Coarse granular cast (/LPF) & $5-10$ & - & - & - & - & Negative \\
\hline B. coli trophozoites & Negative & + & + & $3+$ & Negative & Negative \\
\hline \multicolumn{7}{|l|}{ Spot urine } \\
\hline Total protein (mg/dl) & 1339.4 & - & - & 1679 & - & $2-8$ \\
\hline Creatinine (mg/dl) & 143.79 & - & 491.1 & 100.34 & - & $25-400$ \\
\hline $24 \mathrm{~h}$ urine protein $(\mathrm{g})$ & 9.3 & - & 4.9 & - & - & $<0.15$ \\
\hline Stool examination & - & - & Negative & Negative & Negative & Negative \\
\hline
\end{tabular}

Abbreviations: ALP Alkaline phosphatase, ALT Alanine aminotransferase, AST Aspartate aminotransferase, eGFR Estimated glomerular filtration rate, Hb Hemoglobin, Hct Hematocrit, HPF High-power field,LPF Low-power field, MCV Mean corpuscular volume, RBC Red blood cells, WBC White blood cells

ingesting infective cysts via contaminated water or fresh vegetables or by eating undercooked (that is, improperly grilled) pig intestine. Grilled pig intestine is a very popular dish in some parts of Thailand. Her infection responded well to tetracycline, the recommended first-line treatment. Some authorities recommend that tetracycline should not be used in patients with impaired renal function, because it may cause an increased concentration of BUN due to an antianabolic and diuretic effect [19, 20]. Moreover, impaired excretion results in increased tetracycline accumulation and potential toxicity [21]. Our patient's eGFR was only mildly depressed, she was receiving treatment with steroids, and subsequent serum creatinine measurements did not indicate a deterioration in her renal function due to tetracycline. Alternatives to tetracycline include metronidazole and iodoquinol.

The diagnosis of $B$. coli in our patient was made on the basis of clearly identified morphological features and motility using direct wet preparation, staining, and video microscopy. Other common urine parasites, such as Trichomonas vaginalis (the most common parasite in the genitourinary tract) and E. histolytica, are readily 


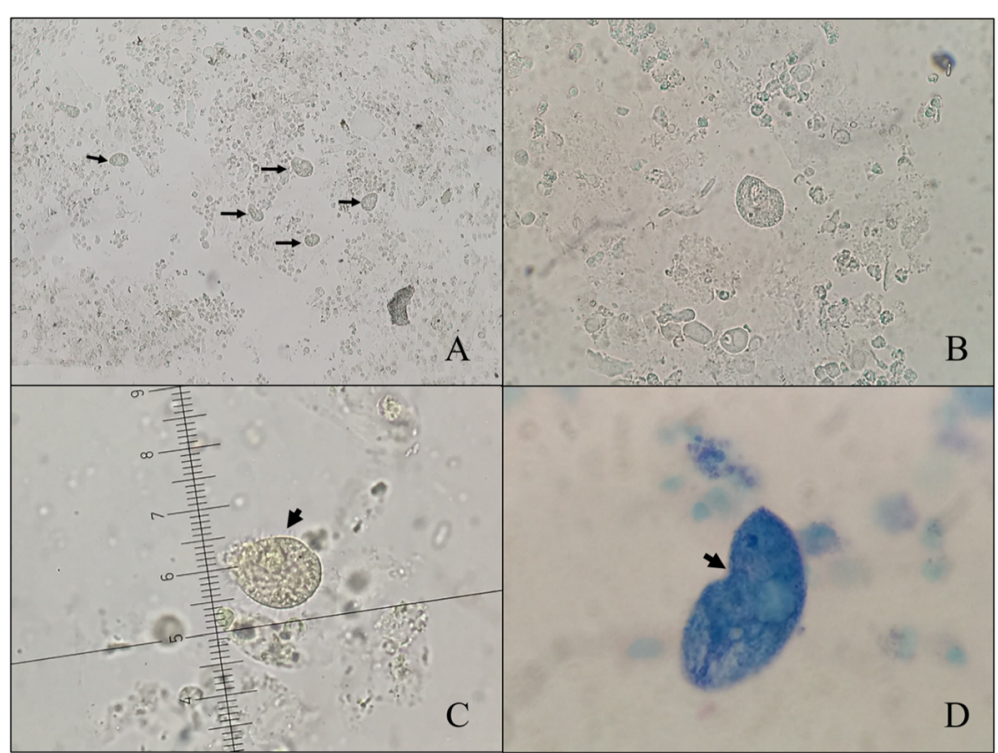

Fig. 1 Detection of B. coli trophozoites in urine samples of our patient with systemic lupus erythematosus. a Several trophozoites (arrows) of different sizes in one low-power field ( $\times 100$ magnification). b A single trophozoite and c ciliated (arrow) trophozoite with a micrometer scale, measuring $30 \times$ $37.5 \mu \mathrm{m}$ ( $\times 400$ magnification). d Wright-Giemsa staining of trophozoite showing cytostome (arrow) and several contractile vacuoles

distinguished on the basis of morphology. B. coli is the only ciliated parasite without flagellae, and its trophozoite movement is unique, a rapid spiral movement produced by the cilia. T. vaginalis trophozoite is the only pathogenic flagellate of the urinary tract; it has a characteristic long, filamentous flagellum and displays jerky movements. $E$. histolytica trophozoites are smaller $(8-30 \mu \mathrm{m})$. Those of B. coli do not have a macronucleus or cilia, and their mobility is characterized by use of their ectoplasmic pseudopods; their cysts are also smaller $(\sim 10-20 \mu \mathrm{m})$ than B. coli cysts, whereas $T$. vaginalis does not have a cyst stage.

\section{Conclusion}

Urinary balantidiasis is rare, is often associated with immunosuppression, and is commonly an incidental finding. It does not usually cause serious renal complications, as was the case in our patient with SLE nephritis. A video recording and Wright-Giemsa staining were useful for the diagnosis. Prevention of B. coli infection lies with better sanitation, providing clean water, avoiding the consumption of undercooked pig intestine, and good hand hygiene, especially for those who work with pigs.

\section{Supplementary information}

Supplementary information accompanies this paper at https://doi.org/10. 1186/s13256-020-02389-7.

Additional file 1. B. coli trophozoite rotary-movement in 400X magnification.

Additional file 2. Direct wet smear of patient urine specimen in 0.85\% $\mathrm{NaCl}$ showing several live B. coli trophozoites in 100X magnification.

\section{Acknowledgements}

The authors are grateful to the Faculty of Medicine, Thammasat University, and the Department of Medical Technology Laboratory, Thammasat University Hospital, for their kind cooperation.

\section{Authors' contributions}

PM conceived and designed the report, searched the literature, made the clinical diagnosis, and prepared the manuscript. KS and SP carried out the clinical diagnosis, data acquisition, and data analysis. PR and AT carried out the clinical diagnosis and interpretation. WRJT critically reviewed the paper for linguistic and scientific content. All authors read and approved the final manuscript.

Funding

None.

\section{Availability of data and materials}

All the data regarding the findings are available within this report.

\section{Ethics approval and consent to participate}

This work was ethically approved by the Human Research Ethics Committee of Thammasat University (COA no. 040/2562).

\section{Consent for publication}

Written informed consent was obtained from the patient for publication of this case report and any accompanying images. A copy of the written consent is available for review by the Editor-in-Chief of this journal.

\section{Competing interests}

The authors declare that they have no competing interests.

\section{Author details}

'Division of Parasitology, Department of Preclinical Sciences, Faculty of Medicine, Thammasat University, Pathumthani 12120, Thailand. ${ }^{2}$ Department of Medical Technology Laboratory, Thammasat University Hospital, Pathumthani, Thailand. ${ }^{3}$ Mahidol Oxford Tropical Medicine Research Unit, Bangkok, Thailand. ${ }^{4}$ Division of Tropical and Humanitarian Medicine, University Hospitals of Geneva, Geneva, Switzerland. 
Received: 18 June 2019 Accepted: 28 April 2020

Published online: 28 May 2020

\section{References}

1. Nakauchi K. The prevalence of Balantidium coli infection in fifty-six mammalian species. J Vet Med Sci. 1999;61(1):63-5.

2. Schuster FL, Ramirez-Avila L. Current world status of Balantidium coli. Clin Microbiol Rev. 2008;21:626-38.

3. Levine ND. Protozoan parasites of domestic animals and of man. Minneapolis: Burgess; 1961.

4. Ponce-Gordo F, Jirku-Pomajbíková K. Balantidium coli. In: Rose JB, JiménezCisneros B, editors. Global water pathogens project. http://www. waterpathogens.org (Fayer R, Jakubowski W, editors. Part 3: Protists). East Lansing: Michigan State University/UNESCO; 2017.

5. Owen IL. Parasitic zoonoses in Papua New Guinea. J Helminthol. 2005;79:114

6. Solaymani-Mohammadi S, Rezaian M, Anwar MA. Human balantidiasis in Iran: an unresolved enigma? Trends Parasitol. 2005;21:160-1.

7. Yazar S, Altuntas F, Sahin I, Atambay M. Dysentery caused by Balantidium coli in a patient with non-Hodgkin's lymphoma from Turkey. World J Gastroenterol. 2004;10:458-9.

8. Anargyrou K, Petrikkos GL, Suller MTE, et al. Pulmonary Balantidium coli infection in a leukemic patient. Am J Hematol. 2003;73(3):180-3.

9. Ferry T, Bouhour D, De Monbrison F, et al. Severe peritonitis due to Balantidium coli acquired in France. Eur J Clin Microbiol Infect Dis. 2004;23: 393-5.

10. Vasilakopoulou A, Dimarongona K, Samakovli A, Papadimitris K, Avlami A. Balantidium coli pneumonia in an immunocompromised patient. Scand J Infect Dis. 2003;35:144-6.

11. Kapur P, Das AK, Kapur PR, Dudeja M. Balantidium coli liver abscess: first case report from India. J Parasit Dis. 2016;40(1):138-40.

12. Sharma S, Harding G. Necrotizing lung infection caused by the protozoan Balantidium coli. Can J Infect Dis. 2003;14(3):163-6.

13. Kaur S, Gupta A. Urinary balantidiasis: a rare incidental finding in a patient with chronic obstructive pulmonary disease. J Cytol. 2016:33:169-71.

14. Umesh S. Balantidium coli on urine microscopy. Natl Med J India. 2007;20: 270.

15. Mane P, Sangwan J, Malik AK, et al. Ann Pathol Lab Med. 2016;3:C-217-9.

16. Karuna T, Khadanga S. A rare case of urinary balantidiasis in an elderly renal failure patient. Trop Parasitol. 2014;4:47.

17. Bandyopadhyay A, Majumder K, Goswami BK. Balantidium coli in urine sediment: report of a rare case presenting with hematuria. J Parasit Dis. 2013:37:283-5.

18. Khanduri A, Chauhan S, Chandola I, Mahawal B, Kataria V. Balantidiosis: a rare accidental finding in the urine of a patient with acute renal failure. J Clin Diag Res. 2014;8:DD03-4.

19. Edwards OM, Huskisson EC, Taylor RT. Azotaemia aggravated by tetracycline. Br Med J. 1970;1(5687):26-7.

20. Shils ME. Renal disease and the metabolic effects of tetracycline. Ann Intern Med. 1963:58:389-408.

21. Kunin CM, Rees SB, Merrill JP, Finland M. Persistence of antibiotics in blood of patients with acute renal failure. I. Tetracycline and chlortetracycline. J Clin Invest. 1959:38:1487-97.

\section{Publisher's Note}

Springer Nature remains neutral with regard to jurisdictional claims in published maps and institutional affiliations.

Ready to submit your research? Choose BMC and benefit from:

- fast, convenient online submission

- thorough peer review by experienced researchers in your field

- rapid publication on acceptance

- support for research data, including large and complex data types

- gold Open Access which fosters wider collaboration and increased citations

- maximum visibility for your research: over $100 \mathrm{M}$ website views per year

At $\mathrm{BMC}$, research is always in progress.

Learn more biomedcentral.com/submissions 